\title{
Autonomy, Vulnerability, Recognition, and Justice
}

\author{
Joel Anderson and Axel Honneth
}

One of liberalism's core commitments is to safeguarding individuals' autonomy. And a central aspect of liberal social justice is the commitment to protecting the vulnerable. Taken together, and combined with an understanding of autonomy as an acquired set of capacities to lead one's own life, these commitments suggest that liberal societies should be especially concerned to address vulnerabilities of individuals regarding the development and maintenance of their autonomy. In this chapter, we develop an account of what it would mean for a society to take seriously the obligation to reduce individuals' autonomy-related vulnerabilities to an acceptable minimum. In particular, we argue that standard liberal accounts underestimate the scope of this obligation because they fail to appreciate various threats to autonomy.

The reason these vulnerabilities have been underestimated, we believe, is because autonomy has generally been understood in an essentially individualistic fashion. The alternative account of autonomy we sketch here highlights the ways in which individuals' autonomy can be diminished or impaired through damage to the social relations that support autonomy. By articulating a conception of autonomy in terms of, more specifically, a theory of mutual recognition, we aim to pinpoint the individualistic bias in liberal accounts and the concomitant underestimation of our dependence on relationships of respect, care, and esteem. We conclude by anticipating some broader implications of this for how proceduralist accounts of social justice ought to be revised. 


\section{From Classic Individualism to Welfare-Rights Protections}

Before challenging the individualism of traditional forms of liberalism (and their underlying accounts of autonomy), it is important to understand this commitment from a historical standpoint. Beginning in the early modern period, a conception of freedom and autonomy gained prevalence in Europe, both in philosophy and everyday life, that has decisively shaped our current understanding of social justice. As individuals increasingly pursued their own independent paths through life, there was an increasing tendency to draw the normative implication that personal freedom and autonomy were a matter of allowing individuals to develop their personally selected pursuits undisturbed. The guiding intuition emerged that the less others constrain one's actions, the greater one's ability to act in accordance with one's own preferences. From the outset, of course, liberal theorists recognized that this freedom was limited. Kant, for one, insisted that liberty and autonomy were to be restrained by the moral requirement that one's chosen pursuits be compatible with everyone else's autonomy. ${ }^{1}$ But these caveats do nothing to alter the core idea that the autonomy of individuals increases with the reduction of restrictions.

This individualistic conception of autonomy not only has historical pedigree; it also has come to seem just obvious to many. Again, this development is understandable. It reflects the important historical process by which, within the social context of modernity, individuals have increasingly shed traditional social ties and role-ascriptions to engage in their

own "pursuit of happiness." But this modern conception of autonomy actually sneaks in an additional component - namely, the idea that individuals realize their autonomy by gaining independence from their consociates. This is not to say that this conception equates autonomy with isolation. But within culture at large, the images that accompany the emergence of this conception of autonomy suggest that any constraints reduce an individual's autonomy. As part of this development, however, an individualistic conception of personal autonomy has crept into modern theories of social justice. The point of creating a just society comes to be seen as allowing people to be as little dependent on others as possible. The conceptual consequences of this individualist strain have been massive. They include not only the idea, for example, that autonomy increases with wealth but also the idea that unchosen membership in a community represents a threat to personal autonomy.

This characterization of liberalism as individualistic is familiar from communitarian political philosophy and some feminist theories of 
autonomy, and in many cases it has been acknowledged by liberal theorists themselves. Even conceptions of justice that focus on reducing interference do not actually assume that everyone really is a rugged individualist. But individualistic accounts certainly are best suited to those who have no need for the benefits of social cooperation or other forms of support. The drive to maximize negative liberty thus seems to rely on a misleading idealization of individuals as self-sufficient and self-reliant. This focus on eliminating interference thus misconstrues the demands of social justice by failing to adequately conceptualize the neediness, vulnerability, and interdependence of individuals. If, by contrast, we recognize that individuals - including autonomous individuals - are much more vulnerable and needy than the liberal model has traditionally represented them as being, a very different picture of the demands of social justice emerges.

The first step in this direction comes from theorists who highlight the extent to which personal autonomy requires the resources and circumstances necessary for actually being able to lead the life one determines to be worthwhile. ${ }^{2}$ This typically shifts the notion of liberal rights to a more positive account, one that includes especially socio-economic rights. This "materialization" of the way in which liberal rights schemes support autonomy (and justice) takes us a long way from hard-edged rugged individualism. It adds significant content to the concept of autonomy by underscoring some of the social conditions for the possibility of autonomy, including the need for education, adequate food and shelter, real opportunities for participating in one's (minority) culture, and so on. Consider, for example, the autonomy of people with mobility-limiting disabilities. Unless physical accommodations are made for such persons wheelchair ramps, accessible vehicles, and so on - their ability to exercise their basic capabilities will be restricted in a way that constitutes a loss of autonomy. In general, the argument here is that the commitment to fostering autonomy - especially of the vulnerable - leads to a commitment, as a matter of social justice, to guaranteeing what one might call the material and institutional circumstances of autonomy. We view this as an important step in the right direction, but it is not our focus here.

Instead, we propose to take up and further develop another expansion of the claims of social justice in line with a conception of autonomy that goes by various names - relational, social, intersubjective, situated, or recognitional - but can be summarized in the claim that "Autonomy is a capacity that exists only in the context of social relations that support it and only in conjunction with the internal sense of being autonomous."3 Although such theories are developed in response to a variety of concerns, 
for our purposes here they serve to highlight vulnerabilities that are overlooked by even the conceptions of social justice and autonomy that accommodate the material and institutional circumstances of autonomy. In the next four sections, we outline our preferred version of such an account, a "recognitional" theory of autonomy. 4 In Sections VI and VII, we turn to the implications that this has for political theory and social justice.

\section{A Recognitional Account of Autonomy}

The key initial insight of social or relational accounts of autonomy is that full autonomy - the real and effective capacity to develop and pursue one's own conception of a worthwhile life - is only achievable under socially supportive conditions. It is an impressive accomplishment that, on the path from helpless infancy to mature autonomy, we come to be able to trust our own feelings and intuitions, to stand up for what we believe in, and to consider our projects and accomplishments worthwhile. We cannot travel this path alone, and we are vulnerable at each step of the way to autonomy-undermining injustices - not only to interference or material deprivation, but also to the disruptions in the social nexus that are necessary for autonomy. In developing a more "social" approach, most theorists tend to focus on one of two points. Some theorists criticize approaches to liberalism or autonomy as "individualistic" for failing to adequately accommodate the centrality of relationships in the lives of autonomous agents, specifically for failing to recognize that meaningful lives can (and generally do) include forms of attachment that are authentic even though they cannot be easily be shed, such as parents' bonds to their children. ${ }^{5}$ Alternatively, defenders of "social" approaches criticize individualistic accounts of autonomy for failing to appreciate the importance of dialogue within an adequate account of the critical reflection central to autonomy. ${ }^{6}$

These are important points to make. But they are not enough to support the core contention from which the shift to a more social account gets its normative point - namely, that one's autonomy is vulnerable to disruptions in one's relationship to others. If this idea is to be accommodated, there are thus reasons to look for a different approach. ${ }^{7}$ One particularly promising approach, in our view, situates agents' social vulnerability in the ways in which being able to lead one's own life is dependent on one's being supported by relations of recognition. ${ }^{8}$ In a nutshell, the central idea is that the agentic competencies that comprise autonomy require 
that one be able to sustain certain attitudes toward oneself (in particular, self-trust, self-respect, and self-esteem) and that these affectively laden self-conceptions - or, to use the Hegelian language, "practical relationsto-self" - are dependent, in turn, on the sustaining attitudes of others. In a tradition going back to Hegel and George Herbert Mead, ${ }^{9}$ these three modes of "relating practically to oneself" can be viewed as being acquired and maintained only through being recognized by those whom one also recognizes. Self-trust, self-respect, and self-esteem are thus neither purely beliefs about oneself nor emotional states, but are emergent properties of a dynamic process in which individuals come to experience themselves as having a certain status, be it as an object of concern, a responsible agent, a valued contributor to shared projects, or what have you. One's relationship to oneself, then, is not a matter of a solitary ego reflecting on itself, but is the result of an ongoing intersubjective process, in which one's attitude toward oneself emerges in one's encounter with an other's attitude toward oneself.

The importance of mutual recognition is often clearest in the breach. Consider, for example, practices and institutions that express attitudes of denigration and humiliation. They threaten individuals' own self-esteem by making it much harder (and, in limit cases, even impossible) to think of oneself as worthwhile. The resulting feelings of shame and worthlessness threaten one's sense that there is a point to one's undertakings. And without that sense of one's aspirations being worth pursuing, one's agency is hampered. This claim is neither exclusively conceptual nor exclusively empirical. It is, of course, psychologically possible to sustain a sense of selfworth in the face of denigrating and humiliating attitudes, but it is harder to do so, and there are significant costs associated with having to shield oneself from these negative attitudes and having to find subcultures for support. And so even if one's effort to maintain self-esteem in the face of denigrating treatment is successful, the question of justice is whether the burden is fair. ${ }^{10}$

If this initial characterization of the autonomy-impairing effects of denigration is plausible, it becomes clear how important an individual's social environment is, since the conditions for autonomously leading one's own life turn out to be dependent on the establishment of relationships of mutual recognition. Prominent among these relationships are (1) legally institutionalized relations of universal respect for the autonomy and dignity of persons (central to self-respect); (2) close relations of love and friendship (central to self-trust); and (3) networks of solidarity and shared values within which the particular worth of members of a 
community can be acknowledged (central to self-esteem). ${ }^{11}$ To illustrate and render plausible the outlines of what we are calling the "recognitional approach," it will be useful to examine each of these three relations-toself, their significance for autonomy, and the social contexts that support them. In addition, however, in order to show that accommodating this shift requires a move away from standard liberal approaches, we need to show that the rights-based individualism of such approaches is inadequate for accommodating the autonomy-related vulnerabilities that the recognitional approach brings to light.

\section{Self-Respect}

We begin with self-respect and with the familiar liberal idea that autonomy and self-respect go hand in hand. Rawls, for example, considers selfrespect to be a basic condition for the pursuit of a good life. Sen argues for the inclusion of the capability to "stand up in public without shame" as a part of the basic capability set to which individuals have a fundamental claim. And Joel Feinberg suggests that " $\ldots$ what is called "human dignity' may simply be the recognizable capacity to assert claims." ${ }^{12}$ If one takes respect (including self-respect) to have, as its object, an agent's authority to raise and defend claims as a person with equal standing, then self-respect can be seen as the affectively laden self-conception that underwrites a view of oneself as the legitimate source of reasons for acting. If one cannot think of oneself as a competent deliberator and legitimate co-author of decisions, it is hard to see how one can take oneself seriously in one's own practical reasoning about what to do. Those with diminished self-respect - with less of a sense of their personal authority - thus are less in a position to see themselves as fully the authors of their own lives. Without self-respect, then, autonomy is impaired.

If we can identify factors that diminish self-respect, we will then have identified ways in which individuals' autonomy is vulnerable and in need of protection. Without getting into an exhaustive list of what diminishes self-respect, we can say that any such list would have to include subordination, marginalization, and exclusion. For these are ways in which individuals are denied the social standing of legitimate co-legislators. They are told, in effect, that they are not competent to shape decisions, and unless they have exceptionally strong inner resources for resisting this message, it will be hard for them to think of themselves as free and equal persons. In this sense, individuals' autonomy is vulnerable to being diminished by subordination, marginalization, and exclusion. ${ }^{13}$ 
It is this particular vulnerability that has made it a central task of social justice to guarantee individual rights. ${ }^{14}$ In guaranteeing rights, a just legal framework protects individuals from these forms of disrespect. Indeed, within contemporary liberal culture, being a bearer of rights has almost come to be synonymous with having the self-respect of a full person. This close linkage is excellent example of the central claim of the recognitional approach we are advocating: it is in virtue of patterns of recognition in this case, legally institutionalized patterns - that the relevant practical relation-to-self is secured.

Clearly, liberalism's commitment to protecting individuals from threats to their autonomy entails a commitment to securing individual rights. But the recognitional approach gives a slightly different twist to this conclusion than do standard liberal approaches. For on the recognitional approach, guaranteeing rights does not ensure autonomy directly (in the negative sense of blocking interference) but rather supports autonomy via the support for self-respect. ${ }^{15}$ As we shall argue later, this shift necessitates a rethinking of standard liberal approaches, even those as sophisticated as Rawls's. ${ }^{16}$

Before taking up that issue, we will first outline the other two practical relations-to-self that, according to the theory of recognition we are defending here, are vital for sustaining autonomy: self-trust and self-esteem. Both cases exhibit the same argumentative structure discussed in connection with self-respect: a practical relation-to-self is crucially important for a component of full autonomy; the development and maintenance of that practical relation-to-self is dependent, in turn, on patterns of recognition; and thus the autonomy of individuals is vulnerable to threats to those patterns. A society's commitment to protecting individuals' autonomy thus entails a commitment to protecting the related recognitional infrastructure: the more-or-less institutionalized relations of recognition that support not only self-respect, but also self-trust and self-esteem.

\section{Self-Trust}

In speaking of "self-trust" (or "basic self-confidence"), we have in mind the characteristic of an agent who has an open and trusting relationship to his or her own feelings, desires, impulses, emotions, and so on. Thus, whereas self-respect has to do with one's capacities for processing various considerations in deliberating about what to do, self-trust has to do with the affectively mediated perceptual capacities by which what is subjectively felt becomes material for deliberation in the first place. Again, 
think of what happens in the breach. There is strong clinical evidence that various forms of trauma - for example, that resulting from rape or torture - cause individuals to view their own feelings with suspicion, and to distrust their own desires. ${ }^{17}$ The relevance of this for autonomy is clear: those who have lost this basic trust have lost the basis for leading their life in accordance with their most basic convictions, since they can no longer trust their desires to be authentically their own. ${ }^{18}$

However far most of us may be from the debilitating effects of such traumatic mistreatment, we all fall along a continuum regarding the particular capacity involved and the degree to which it is fostered by our social context. Self-trust is a vital component of anyone's autonomy because of the complexity of our access to our feelings, yearning, fears, regrets, and so on. In part, the importance of self-trust stems from the difficulty of the interpretive work that must be done to understand oneself - and from the elusiveness of first-person authority reports. ${ }^{19}$ But even these difficulties are radicalized by a further insights, associated with the "critique of the subject" - namely, the discovery of the unconscious. One of the enduring accomplishments of psychoanalytic theory lies in exposing the illusion both of complete transparency about our motives and of perfect harmony among our desires, even in the case of perfectly of autonomous agents. This unavoidably inchoate, shadowy, and conflicted inner life suggests the need for a more polyvocal conception of how autonomous individuals relate to their desires, impulses, fantasies, and other dimensions of subjectivity. ${ }^{20}$

Of course, autonomy clearly requires that one be constituted in such a way that openness to both these creative impulses does not mean that they simply take over the self. But the point of emphasizing polyvocality is to underscore that it is also crucial to avoid psychological rigidity. And to appreciate how much self-trust contributes to autonomy, it is important to see that it is not entailed by standard requirements of being rational or responsive to reasons, which is the way in which psychological rigidity is often handled in the philosophical literature..$^{21}$ In addition to being flexible enough to respond appropriately to life-changes, autonomous agents are also open to those sources of identity and choice that underlie practical reasons, in the primitive and inchoate urges, impulses, longings, and despairings that can come to be transformed into reasons. Thus, in this sense, the model of the autonomous agent that emerges from taking seriously the polyvocal character of the self is of a person who is not only freed from compulsive behavior patterns but is also open to new, as-yet undisclosed desires. This idea is reflected in the shift within the 
psychoanalytic conception of maturity, from a capacity for controlling one's inner urges (that is, "ego strength") to the potential for inner dialogue, for openness to both a multiplicity of internal voices and a variety of communicative relations to them. ${ }^{22}$

As with self-respect, however, self-trust is not a solo accomplishment. Its acquisition and maintenance are dependent on interpersonal relationships in which one acquires and sustains the capacity to relate to this dynamic inner life. And in the case of self-trust in particular, there is strong evidence from object-relations theory and intersubjectivist approaches to social psychology that self-trust emerges especially within intimate relationships. ${ }^{23}$ Especially given the ambivalent and conflicted nature of much of our inner life, the genuine openness characteristic of fully free and autonomous reflection and deliberation can be risky. The courage to engage with one's deepest feelings both openly and critically is facilitated by the sure love of others and the self-trust it supports. And insofar as being comfortable and confident doing this is essential to selfunderstanding, critical reflection, and thus autonomy, it becomes clear that there is an internal connection between the openness and freedom of one's inner life and the openness and freedom of one's social context.

The crucial implication of this discussion is that individuals' autonomy is also vulnerable, in principle, to anything that diminishes self-trust, either directly or indirectly. With regard to direct effects, we can note that because "intimate violations" such as rape and torture are so harmful to agents' self-trust and hence their autonomy, a society committed to protecting individuals has an additional reason to be committed to preventing such violations. With regard to indirect effects, the key result, for our purposes, is that a society's commitment to protecting the conditions for autonomy can also be seen to entail a commitment to protecting the kinds of relationships within which self-trust is developed and fostered. Thus, for example, work/family policies (such as parental leave) can be seen as part of a commitment to protecting and promoting one important component of the capacities constitutive of autonomy. ${ }^{24}$

\section{Self-Esteem: Semantic Vulnerability}

Someone who was protected from the exclusions that undermine selfrespect and the threats that undermine self-trust could, however, still have his or her autonomy jeopardized in another way (already mentioned in Section II): the conditions for developing a sense of self-worth and self-esteem can be impaired as a result of patterns of humiliation 
and denigration and in a way that renders a person less able to be selfdetermining with regard to his or her projects. This potential threat to autonomy raises, in turn, further questions about social justice and the guaranteeing of autonomy.

To make clear the importance of self-esteem for autonomy, we can begin with an extension of the point from the previous section. For the self-interpretive activity central to autonomous reflection presupposes not only a certain degree of quasi-affective openness but also certain semantic resources. Again, this stems from one of the genuine insights of the twentieth-century critiques of modern - "Cartesian" - conceptions of the subject: individuals cannot decide for themselves what their (speech) acts mean. Rather, determining the worth and meaning of one's activities is fundamentally framed by the semantic and symbolic field in which that reflection occurs - what gets termed variously the "space of reasons" (McDowell), "horizon of significance" (Taylor), "regime of truth/knowledge" (Foucault), or socio-cultural means of need-interpretation (Fraser). ${ }^{25}$ Thus, for example, the very possibility of being "openly lesbian" or "a stay-at-home dad" is framed by a whole constellation of evaluatively loaded ways of talking.

It is the unavoidably evaluative character of this symbolic-semantic field that has the crucial implications regarding autonomy. For if the semantic resources available for thinking about one's way of life are negatively loaded - if, for example, "stay-at-home dad" is taken to be a euphemism for "unemployed" - then it becomes hard to view it as worthwhile. Not impossible, perhaps. But without an especially high level of personal resilience, subcultural support, and persistent effort - that is, without other (often limited) sources of self-esteem - marginalized ways of life cease to be genuine options for individuals.

In itself, this restriction of options might not be seen as a threat to autonomy. But it has always been one of the strengths of the liberal tradition to highlight the degree to which such restrictions pose a threat to the individuality of persons. Think, for example, of J.S. Mill's On Liberty. But once we grant that those individual lifestyles provide the basis for a sense of being worthwhile as a consequence of their getting a certain confirming "uptake" within the social world, then the richness of the identity available to any individual can thus be restricted with limitations on the richness of the available semantic field. To the extent to which one's way of life not only fails to get uptake but is an active target of denigration and humiliation, the task of pursuing one's way of life as meaningful is even more fraught with difficulty. 
In connection with autonomy, we can add a point about the effects that such denigration has on a person's sense of agency and personal effectiveness. This is a more formal consideration: to the extent to which one lacks a sense that what one does is meaningful and significant, it becomes hard to pursue it wholeheartedly. There is at least a tension between pursuing that way of life and thinking of oneself as doing something that makes sense. And, as David Velleman argues, being able to make sense of what it is we are doing is intimately tied up with actually doing it. ${ }^{26}$ Thus, a socio-cultural environment that is hostile to considering what one does meaningful is demoralizing. Because of the way they can undermine selfesteem, systematic patterns of denigration thus pose a threat not merely to the happiness or identify but to the agency of those affected.

In short, for the exercise of autonomy, individuals are not only dependent on a semantic-symbolic environment that "meets them halfway" for enabling a rich self-interpretation; they are also vulnerable to hostile and denigrating semantic-symbolic environments that more directly assault or limit their autonomous agency. Accordingly, a conception of social justice that is seriously committed to protecting the autonomy of individuals must include a protection against threats of denigration. ${ }^{27}$

Pulling the strands of the last three sections together, we have the outlines of a recognitional model according to which autonomy represents an emergent property of individuals as the bearers of certain socially situated capabilities. This theoretical shift makes it much more straightforward to articulate and theorize the link between mutuality and individual enablement. Full autonomy - the real and effective capacity to develop and pursue one's own conception of a worthwhile life - is facilitated by relations-to-self (self-respect, self-trust, and self-esteem) that are themselves bound up with webs of social recognition. But self-trust, selfrespect, and self-esteem remain more or less fragile achievements, and their vulnerability to various forms of injury, violation, and denigration makes it a central matter of justice that the social contexts within which they emerge be protected.

\section{Recognition and the Language of Rights}

In returning to questions of social justice and political liberalism, we now take up the question of the extent to which this recognitional approach to autonomy raises challenges for liberalism. In particular, we shall consider two attempts to accommodate the vulnerabilities we have been discussing, attempts that we see as not entirely successful. First, we discuss, in a cursory 
fashion, the limitations of trying to articulate in the language of rights the imperatives generated by these vulnerabilities. Then, in the next section, we discuss, at somewhat greater length, the question of whether Rawls's theory of justice can accommodate these considerations adequately.

Initially, a rights-based approach might seem perfectly well suited to articulating the idea that a commitment to social justice requires that society protect individuals against autonomy-related vulnerabilities. As we noted earlier, rights-based approaches have tended to focus on the conditions for self-respect - such as rights to full participation - to the exclusion of self-trust and self-esteem. But it might be argued that we have not yet shown that the claims to conditions supportive of the acquisition and maintenance of self-esteem and self-trust could not be accommodated within the language of rights, at least as rights-claims vis-à-vis the circumstances of justice. This is what has been attempted, for example, in the politics of identity, where groups have sought to claim a right to be recognized, as individuals, for their cultural needs. But the idea of addressing these needs for recognition in the vernacular of rights has turned out to be a quagmire. The central problem is that it misses its target, for what one needs is to be loved or esteemed - and precisely not because one has a legal claim to it. Moreover, attempts to conceptualize human needs and vulnerability in the domains that support self-trust and self-esteem in terms of rights that can be individually possessed are strained beyond plausibility: it is particularly clear here that these are fundamentally relational circumstances. Knowing oneself to be the object of very personal concern or having the sense that one's undertakings are considered worthwhile - these are not matters that one person has in independence from a relationship. They are emergent properties of relationships of a certain sort.

Once this point is acknowledged, it becomes attractive to reconsider, more radically, the individualistic understanding of rights as well. For rights too have this general intersubjective structure. These rights - and the power and freedom they accord to individuals - are actually the result of members of a community recognizing each other as free and equal. To view them as free-standing is to confuse an emergent property for something independently existing. According to this non-individualistic conception of the way in which rights support personal autonomy, first developed by Hegel, gains in freedom and power come from having others see one's needs and aspirations as legitimate. These gains are welcome at the individual level, of course, and that is where they are subjectively experienced: I can do things I couldn't do before. But they remain, 
essentially, the product of social relationships with a decisive characteristic: individuals mutually recognize, acknowledge, and accept each other as consociates. It is in this sense that traditional rights language is problematically individualistic, in that it conceptualizes rights-guaranteeing relations as a matter of specific powers that can be distributed among individuals as if they were individual possessions.

Rights do, of course, have a central place in any plausible conception of how a just society protects and enables individual autonomy. The question is whether they can do it alone. Without denying their importance, we think it is clear that the medium of rights is inadequate to address the full vulnerability of humans. Legal relations are a clumsy medium for securing many aspects of an individuals' ability to develop and pursue their own conception of a worthwhile life. An adequate approach must start out from the broader range of social institutions and interpersonal contexts within which one finds the recognitional relations crucial for autonomy.

\section{Rethinking Proceduralist Justice in Light of the Recognitional Model}

Up to now, we have not yet considered how various protections from autonomy-related vulnerabilities ought to fit together or how to set priorities among these various vulnerabilities. Answering these questions involves developing a substantive normative theory. Here, however, our concern is with the prior question as to the procedure for justifying any such answers. This is the task of specifying the standpoint from which to determine the content of social justice.

Within political theory today, there is widespread agreement on the proceduralist assumption that normative justification is to be located in the deliberative contexts in which the potential members of the relevant society reach an understanding, under real or fictitious conditions of impartiality, about the principles that are to regulate their future cooperation. This underlying demand for impartiality is intended to both guarantee the general acceptability of the results and provide a principle of inclusivity vis-à-vis all members of society. The principles on which the participants in this deliberative social contract would agree serve to regulate the relations between persons, represented as interested in the most autonomous possible realization of their individual life-plans.

Rawls's theory of justice as fairness represents the most influential version of this proceduralism. The question we now wish to pose is whether a 
recognitional understanding of autonomy-relevant vulnerabilities necessitates a rethinking of Rawls's version of this proceduralism. We shall argue that to some extent it does. This leaves open the question of whether the best way to accommodate the recognitional insights into these vulnerabilities is through modifying proceduralism or adopting a non-proceduralist approach. ${ }^{28}$

Starting out from the idea that a fictional deliberative context is the best way to operationalize insights into universally acceptable principles of justice, the first task is to determine the normative presuppositions for an impartial standpoint, one that includes all participants. The idea is to ensure that none of the parties to the deliberations endorses a particular proposal only because he or she could benefit from it. This goal of generating an impartial standpoint through purely procedural means is what led Rawls to introduce the idea of a "veil of ignorance," as a way to ensure that those seeking to find agreement on principles governing their fair cooperation are not permitted to have any knowledge of their talents or social position. ${ }^{29}$ That subtle move provides a way of ensuring that the parties in this thought experiment must be thought of as neutral legislators, since they cannot have any self-regarding interests. For the rest, Rawls (like almost all contract theorists before him) attributes to the parties merely instrumental capacities for practical reasoning, in order to avoid having to take up complex and controversial claims about the moral character of humans.

In the present context, we are not interested in discussing this part of Rawls's theory, although from the standpoint of Hegel and other intersubjectivistic thinkers, this is a highly problematic move, insofar as it makes it very difficult to explain why the parties should subsequently be motivated to abide by the agreed-upon principles..$^{30}$ Rather, we are interested in the extent to which the Rawlsian characterization of the veil of ignorance ends up allowing the fact of human intersubjectivity to disappear more than necessary from view. Don't the parties need to have some awareness - even within the procedural constraints that are to generate impartiality - of their intersubjective vulnerability if they are to qualify as human, as the sort of creatures for whom the institutions of justice are so essential? ${ }^{1}$

What makes this more than an artificial question is the way in which it reveals the impossibility of determining the justificatory procedures in complete independence from assumptions about the defining characteristics of human personhood. Rawls insists that the parties in the original position should not have knowledge of what people in the society are 
like, except the most basic features of their instrumental rationality. ${ }^{2}$ Given what we have said thus far, this suggests that Rawls allows the veil of ignorance to fall a bit too low. For if liberal justice is centrally about protecting individuals in areas in which they are vulnerable - especially as it pertains to threats to their autonomy - then it would seem to be of vital importance that the parties in the original position have a clear understanding of the recognitional needs that must be met if individuals' autonomy is to be adequately protected and enabled. Unless the parties share this understanding, it is hard to see how the principles they develop could do justice to these vulnerabilities and needs.

There are several responses open to Rawls. He could insist that in the original position, parties should indeed be ignorant of empirical considerations regarding human vulnerabilities, but that these issues can be addressed at the "legislative" level. This is the move that he makes, for example, with issues of health care policy, where he argues that although considerations regarding the prevalence of various illnesses are excluded from deliberations within the original position, they can be taken up later, in the legislative stage. ${ }^{33}$ Similarly, it might be that the specification of the primary goods, within the original position, ought not to admit considerations about the nature of our vulnerability to injury to our self-trust, self-respect, and self-esteem, but that those considerations could be taken up in the legislative stage, without their needing to be built into the fundamental principles of justice. The problem with this is not only that if the recognitional approach is on the right track, the capacities at issue are more extensive than the faculty or "moral power" that Rawls discusses for having "a capacity for a conception of the good." 34 More straightforwardly, the autonomy-related capacities that are vulnerable to injustice are so widely and deeply implicated in central aspects of deliberation that it would be foolhardy to trust this to a subsequent legislative stage.

But perhaps the more fundamental issue at stake here has to do with the degree to which we should appeal to quasi-empirical aspects of human personhood in developing a conception of justice for liberal societies. Indeed, Rawls insists that the notion of a "person" that is essential to his conception of justice as fairness is "normative and political, not metaphysical or psychological." 35 Thus, the fact that we are vulnerable is to be accommodated within justice as fairness by saying that the basic structure needs to protect persons from threats to their "moral power" to form a conception of a worthwhile life-plan, and thus needs to secure the primary goods necessary for that. And this is quite extensive, for what is at issue is a matter of the requisite powers of moral personality and the 
other capacities that enable persons to be normal and fully cooperating members of society over a complete life. ${ }^{6}$ It is not implausible, for example, that it could include the same conditions for the development of autonomy that we have specified here - self-trust, self-respect, and selfesteem. The details would still need to be worked out, of course, but Rawls does have impressive resources for accommodating the sorts of points we have been making. Indeed, Rawls's discussion of self-respect already suggests that the parties in the original position must be aware of some of their needs for recognition. For it makes sense for parties to include the basic intersubjective good of self-respect in their deliberations over the basic structure of a just society only if they already understand that the conception and pursuit of their life-plans depend fundamentally on the esteem of others. Perhaps, then, the recognitional account of autonomy we have been developing identifies an area where important work needs to be done, but more as an elaboration of the basic Rawlsian approach than as a significant departure from it.

If this were all we accomplished here, it would already be a substantive contribution. We see, however, three grounds for thinking that Rawls's model still needs to be revised to accommodate the recognitionalist account of autonomy: ( 1 ) it needs to be more open to considerations based on what we know about human persons; (2) it needs to address more broadly the ways in which a society's recognitional infrastructure can leave the autonomy of individuals unacceptably vulnerable; and (3) it needs to be acknowledged that the broad relevance of recognitional conditions necessitates a shift away from exclusively distributive issues. In the remainder of this chapter, we sketch out these three points and argue that they do, indeed, suggest the need for significant revisions to basic commitments of (Rawlsian) liberalism.

Consider, first, the issue of how relevant psychological considerations ought to be in deliberations about principles of justice. There are, of course, good reasons for not basing a conception of justice on a conception of human nature. The deeper one gets into claims about what it is to be "truly human," the greater is the danger that the agenda for establishing justice will be set by (sub) culturally biased claims about what constitutes a proper form of life. But in his effort to accommodate the fact of reasonable pluralism, Rawls's sharp split between political and "metaphysical" claims regarding the nature of human persons is neither necessary nor, ultimately, defensible. It is not necessary because claims about human qualities need not be parochial: some basic needs are more or less universal, and as recent "capabilities approaches" have argued, an appeal 
to basic human needs and characteristics are not obviously incompatible with a commitment to inclusive, universalistic forms of liberalism. ${ }^{37} \mathrm{We}$ see no reason why a theory of justice ought to count as disrespecting pluralism simply as a result of incorporating empirical considerations about human vulnerabilities, such as the effect that certain forms of neglect have on the potential for forming rewarding personal relationships. The burden of proof is rather on those who would say that there are necessary illiberal effects resulting from allowing a given set of considerations to carry weight in deliberations within the original position. Moreover, the purportedly sharp split between "metaphysical" and "political" claims about personhood tends to break down upon closer examination. After all, everything we know about the conditions required for acquiring the two moral powers comes from experience with human persons. This knowledge is clearly relevant to issues of justice, but it is entirely unclear how this could be anything other than "psychological" knowledge about the nature of humans.

But even if we were to follow Rawls in limiting ourselves to a "normative/political" conception of the person (and to refrain from making claims about the nature of human persons), there is a second reason to think that the recognitional approach we have outlined here would require more a transformation than an extension of his approach: it improperly limits the scope of what goes into the notion of the "moral power" to conceive and pursue a way of life, or even what goes into the conditions for acquiring the positive disposition toward oneself that Rawls refers to as "self-respect (or self-esteem)." ${ }^{8}$ In part, this is a matter of not giving much attention to the recognitional conditions for acquiring and maintaining self-trust (and thus of the associated openness to the creative impulses stemming from inner dynamics). Indeed, when Rawls says that the parties in the original position can be thought of as "heads of families," 39 he is concerned with the idea of responsibility for the welfare of other family members and of descendents, rather than of the importance of maintaining the intimate relations crucial for self-trust. Similarly, when Rawls discusses self-esteem, the social relations that he focuses on are limited to clubs and voluntary associations. $4^{\circ}$ But this gives a far too restricted role to much more broad-reaching factors such as symbolic-semantic resources and the way those cultural patterns frame the range of available options. But most fundamentally, the point is that parties in the original position need much better understanding of these conditions for acquiring self-respect and self-esteem than Rawls equips them with. And including this knowledge - even when it is not centrally 
about human psychology - will unavoidably introduce into the discussion of the principles of justice issues about what qualities to promote, both as essential aspects of the autonomy-sustaining relations-to-self we have been discussing and as indirect conditions for the acquisitions of those capacities..$^{1}$

Finally, and perhaps most speculatively, the intersubjectivism of the recognitional approach seems to require a reconceptualization of the nature of justice. As we have seen, the standard liberal combination of legally protected liberties and material resources does not exhaust the requisite conditions for fostering and protecting individuals' autonomy, given the additional dimensions of autonomy and the associated vulnerabilities. Once it is acknowledged, further, that even these preliminary conditions for autonomy are not a resource that can be distributed at will, then it becomes clear that we - like the parties in the original position - must undertake a rethinking of what the object of a theory justice is. From the perspective of asking what the conditions are that equally guarantee the personal autonomy of all members of society, and equally protect them in their intersubjective vulnerability, the main focus of application for principles of justice becomes the structure and quality of social relations of recognition. As a result, this liberal conception of justice loses its character as a theory of distribution. It becomes instead - to put it somewhat provocatively - a normative theory of the recognitional basic structure of a society. What comes, then, to take the place of principles of just distribution are principles governing how the basic institutions of society secure the social conditions for mutual recognition. And that is a profoundly different - and largely unexplored - way of thinking about social justice.

\section{Conclusion}

We have proposed here a recognitional model of autonomy that emphasizes the intersubjective conditions for being able to lead one's life as one's own, and sketched some implications that this may have for rethinking basic features of the liberal political order. Central to that model of autonomy is the idea that the acquisition, maintenance, and exercise of the array of competencies comprising autonomy depends on the establishment of particular ways of "relating to oneself practically," especially selfrespect, self-trust, and self-esteem. Because these are, in turn, bound up with various social relations of recognition, autonomy turns out to have, as a condition of its possibility, a supportive recognitional infrastructure. 
Because agents are largely dependent on this recognitional infrastructure for their autonomy, they are subject to autonomy-related vulnerabilities: harms to and neglect of these relations of recognition jeopardize individuals' autonomy.

This expanded conception of the ways in which individuals' autonomy can be undermined suggests an expanded scope for the core liberal obligation to guaranteeing individual autonomy. There are, to be sure, resources within liberalism for accommodating this expanded scope. If our argument here is sound, however, those resources are not entirely adequate. Liberalism faces a new challenge of doing justice to the profoundly intersubjective nature of autonomy.

\section{Notes}

We would like to thank Bert van den Brink, Pauline Kleingeld, and Chris Zurn for comments on a previous draft of this chapter.

1. Immanuel Kant, "Groundwork for a Metaphysics of Morals," in Mary J. Gregor (trans. and ed.), Practical Philosophy (Cambridge: Cambridge University Press, 1996), pp. $43^{-108 .}$

2. A diverse sampling of such views might include Robert Young, Autonomy: Beyond Negative and Positive Liberty (New York: St. Martin's Press, 1986); Marina Oshana, "Personal Autonomy and Society," The Journal of Social Philosophy 29 (1998): 81-102; Amartya Sen, Development as Freedom (New York: Knopf, 1999); Joseph Raz, The Morality of Freedom (Oxford: Clarendon, 1986); John Rawls, A Theory of Justice (Cambridge, MA: Harvard University Press, 1971); Thomas W. Pogge, Realizing Rawls (Ithaca, NY: Cornell University Press, 1989); and Jürgen Habermas, Between Facts and Norms, trans. William Rehg (Cambridge, MA: MIT Press, 1996).

3. Jennifer Nedelsky, "Reconceiving Autonomy: Sources, Thoughts, and Possibilities," Yale Journal of Law and Feminism 1:7 (Spring 1989): 25. See also, for example, Catriona Mackenzie and Natalie Stoljar, "Autonomy Refigured," in Mackenzie and Stoljar (eds.), Relational Autonomy: Feminist Perspectives on Autonomy, Agency, and the Social Self (New York: Oxford University Press, 2000), 3-31; Marilyn Friedman, "Autonomy in Social Context," in Creighton Peden and James P. Sterba (eds.), Freedom, Equality, and Social Change (Lewiston, NY: Edwin Mellen, 1989), pp. 158-69; John Christman, "Autonomy and Feminism"; Meyers, Self, Society, and Personal Choice, and Joel Anderson, "Autonomy and the Authority of Personal Commitments: From Internal Coherence to Social Normativity," Philosophical Explorations 6 (2003): 90-108.

4. We are using "recognitional" to denote attitudes, experiences, vulnerabilities, and so on. that are related to claims to recognition. In some cases, it also serves to designate an approach based on recognition (as an equivalent for "anerkennungtheoretisch"). 
5. Regarding the importance of such "unsheddable" attachments, see John Christman, "Relational Autonomy, Liberal Individualism, and the Social Constitution of Selves," Philosophical Studies 117 (2004): 143-64; Harry Frankfurt, Necessity, Volition, and Love (New York: Cambridge University Press, 1999); Sarah Buss, "Autonomy Reconsidered," Midwest Studies 9 (1994): 95-121; Eva Feder Kittay, Love's Labor: Essays on Women, Equality and Dependency (New York: Routledge, 1999). See also, however, Marilyn Friedman's discussion of overlooked sensitivity to the relational within liberal accounts of autonomy in "Autonomy and Social Relationships: Rethinking the Feminist Critique," in Autonomy, Gender, Politics. (New York: Oxford University Press, 2003), $81-97$.

6. See Diana T. Meyers, Self, Society and Personal Choice (New York: Columbia University Press, 1989); Seyla Benhabib, Situating the Self: Gender, Community, and Postmodernism in Contemporary Ethics (New York: Routledge, 1992); Charles Taylor, "The Dialogical Self," in David R. Hiley, James F. Bohmann, and Richard Shusterman (eds.) The Interpretive Turn: Philosophy, Science, Culture (Ithaca, NY: Cornell University Press, 1991), 304-14; Joel Anderson, "A Social Conception of Personal Autonomy: Volitional Identity, Strong Evaluation, and Intersubjective Accountability" (Ph.D dissertation, Northwestern University, 1996); and Jürgen Habermas, "Individuation through Socialization: On George Herbert Mead's Theory of Subjectivity," in Postmetaphysical Thinking, trans. William Hohengarten (Cambridge, MA: MIT Press, 149-204).

7. Clearly, not everyone is interested in developing a social account, and many theorists may well find this to be a mistaken move. To show, against them, that the recognitional approach is the correct one would require a different argument than what we provide here. Our explicit aims, however, are more limited: first, to show that the recognitional approach has an initial appeal and plausibility; and second, to show that if one adopts this approach, then there are certain interesting implications that follow from this.

8. For further development of these ideas - as well as references to the empirical evidence in favor of them - see Axel Honneth, The Struggle for Recognition: The Moral Grammar of Social Conflict, trans. Joel Anderson (Cambridge: Polity Press, 1995); "Invisibility: The Moral Epistemology of 'Recognition'," The Aristotelian Society, supp. vol. LXXV (2001): 111-26; "Grounding Recognition: A Rejoinder to Critical Questions," trans. Joel Anderson, Inquiry 45 (2002): 499-519; Suffering from Indeterminacy: An Attempt at a Reactualization of Hegel's Philosophy of Right (Assen: Van Gorcum, 2000); and (with Nancy Fraser) Redistribution or Recognition? A Political-Philosophical Exchange, trans. J. Golb, J. Ingram, and C. Wilke (New York: Verso, 2003).

9. On the historical sources, see especially G. W. F. Hegel, "Jena Lectures on the Philosophy of Spirit," in Leo Rauch (ed. and trans.), Hegel and the Human Spirit: A Translation of the Jena Lectures on the Philosophy of Spirit (I 805-06) with Commentary (Detroit: Wayne State University Press, 1983); George Herbert Mead, Mind, Self, and Society (Chicago: University of Chicago Press, 1955); and their discussion in Honneth, Struggle for Recognition, chapters 1-4. 
10. Note that our claim is merely that part of what makes practices of denigration, disrespect, and intimate violation unjust is that they impair autonomy or put that autonomy at significant risk. Obviously, these practices can also be criticized directly as subordinating or painful.

11. Two points need to be noted about this tripartite distinction of "spheres" of recognition relations, as it has been a source of controversy in discussions of the recognitional approach. (See, for example, Nancy Fraser's contributions to Redistribution or Recognition?) First, these three domains are not transhistorical "givens" but are rather established and expanded through social struggles that are fueled by feelings of outrage and indignation over recognition being denied or withheld. For our purposes here, we do not even need to presuppose that these are the only three relations of recognition, since all we are arguing here is that there are at least these three dimensions along which we are vulnerable. Second, since allowing for the historical contingency of these spheres (and the corresponding claims about self-trust, self-respect, and self-esteem being necessary for autonomy) opens up potential problems of normativity, it is important to note that the account we are presenting here needs to be supplemented by an account of how the historical emergence of normative claims for recognition can nonetheless have critical authority. Because of limited space, the reader will have to look elsewhere for that account - for example, in Honneth, The Struggle for Recognition, chapter 9; "Grounding Recognition," and "The Point of Recognition," in Fraser and Honneth, Redistribution or Recognition?, pp. $256-65$.

12. John Rawls, A Theory of Justice, $\S 67$; Sen, "Social Exclusion: Concept, Application, and Scrutiny," Social Development Papers No. 1 (Asian Development Bank); and Feinberg, "The Nature and Value of Rights," in Rights, Justice, and the Bounds of Liberty (Princeton: Princeton University Press, 1980), p. 143.

13. See also Avishai Margalit's development of the idea that "a decent society is one whose institutions do not humiliate people" in The Decent Society, trans. Naomi Goldblum (Cambridge, MA: Harvard University Press, 1996).

14. See, for example, Rainer Forst's discussion of "legal autonomy" in "Political Liberty" (Chapter 10 in the present volume).

15. Andreas Wildt, "Recht und Selbstachtung, im Anschluss an der Anerkennungslehren von Fichte und Hegel," in Michael Kahlo, Enst A. Wolf, and Rainer Zaczyk (eds.), Fichtes Lehre von Rechtverhältnis (Frankfurt am Main: Klosterman, 1992), $127 \mathrm{ff}$.

16. In speaking of "standard" liberal approaches, we intend to set to one side "perfectionist" approaches, many of which share our view that guaranteeing rights is a matter of guaranteeing access to valuable social practices, many of which presuppose, in turn, that one be able to act autonomously. See, for example, Raz, The Morality of Freedom; George Sher, Beyond Neutrality: Perfectionism and Politics (Cambridge: Cambridge University Press, 1997); and Steven Wall, Liberalism, Perfectionism and Restraint (New York: Cambridge University Press, 1998). For an excellent discussion, see Bert van den Brink, The Tragedy of Liberalism: An Alternative Defense of a Political Tradition (Albany: SUNY Press, 2000), chapter 4 . 
17. Elaine Scarry, The Body in Pain: The Making and Unmaking of the World (Oxford: Oxford University Press, 1985); Trudy Govier, "Self-Trust, Autonomy, and Self-Esteem," Hypatia 8 (1993), 99-120; Dorothy Brothers, Falling Backwards: An Exploration of Trust and Self-Experience (New York: Norton, 1995); and Susan J. Brison, Aftermath: Violence and the Remaking of a Self (Princeton: Princeton University Press, 2003).

18. Of course, the ability to question whether one's desires are "one's own" is an important component of autonomy more generally. But normally, when desires are questioned, they are questioned against a background of a web of convincing desires and values. The difficulty faced by those who have little self-trust is that so many of their most basic desires are being doubted that the process of reflection can get no foothold.

19. See, for example, Charles Taylor, Sources of the Self: The Making of Modern Identity (Cambridge, MA: Harvard University Press, 1989), part 1; Richard Moran, Authority and Estrangement : An Essay on Self-Knowledge (Princeton: Princeton University Press, 2001); Joel Anderson, "Competent Need-Interpretation and Discourse Ethics," in James Bohman and William Rehg (eds.), Pluralism and the Pragmatic Turn: The Transformation of Critical Theory (Cambridge, MA: MIT Press, 2001), 193-224; and John Christman, "Autonomy, SelfKnowledge, and Liberal Legitimacy" (Chapter 14 the present volume, Section II).

20. See Diana T. Meyer's discussion of "polyvocal” subjectivity in Subjectivity and Subjection: Psychoanalytic Feminism and Moral Philosophy (New York: Routledge, 1994), chapter 4-5; see also her discussion of skills of self-discovery in "Decentralizing Autonomy: Five Faces of Selfhood" (Chapter 12 in present volume). The connection between this conception of autonomy and the "critique of the subject" is further elaborated in Axel Honneth, "Decentered Autonomy: The Subject After the Fall," in Charles Wright (ed.) The Fragmented World of the Social: Essays in Social and Political Philosophy (Albany, NY: SUNY Press, 1995), 261-72.

21. See, for example, Alfred Mele, Autonomous Agents: From Self-Control to Autonomy (New York: Oxford University Press, 1995), 131-43.

22. For a further development of this idea, see Honneth, "Postmodern Identity and Object-Relations Theory: On the Supposed Obsolescence of Psychoanalysis," Philosophical Explorations 3 (1999): 225-42.

23. See especially Donald Winnicott, The Maturational Processes and the Facilitating Environment (London: Hogarth Press, 1965); see also, Honneth, The Struggle for Recognition, pp. 95-107.

24. Along related lines, Christopher Beckett has recently argued that liberalism's commitment to promoting autonomy underwrites policies that encourage marriage-like relationships ("Autonomy, Liberalism, and Conjugal Love," Res Publica 9 [2003]: 285-301). Also crucially important for the protection of the contexts that nourish self-trust is a domain of privacy, which is not to be understood exclusively in terms of rights; see Beate Rössler, Der Wert des Privaten (Frankfurt am Main: Suhrkamp, 2001).

25. See, respectively, John McDowell, Mind and World (Cambridge, MA: Harvard University Press, 1994); Charles Taylor, Sources of the Self; Michel Foucault, 
P1: KaD

o521839513co6.xml CY5ooB/Christman $\quad$ o $5^{21} 8395^{1} 3 \quad$ August 24, $2004 \quad 4: 5^{\circ}$

Order of Things: An Archaeology of the Human Sciences, trans. A. M. Sheridan Smith (New York: Pantheon Books, 1970); and Nancy Fraser, "Struggle over Needs: Outline of a Socialist-Feminist Critical Theory of Late Capitalist Political Culture," in Unruly Practices: Power, Discourse, and Gender in Contemporary Social Theory (Minneapolis: University of Minnesota Press, 1989), pp. 161-87. 26. See, for example, J. David Velleman, Practical Reflection (Princeton: Princeton University Press, 1989).

27. See Margalit, The Decent Society; and Will Kymlicka, Multicultural Citizenship (Oxford: Oxford University Press, 1995).

28. For more historical development of the following argument, focused on Hegel, see Honneth, "Gerechtigkeit und kommunikative Freiheit. Überlegungen im Anschluss an Hegel," in B. Merker, G. Mohr, and M. Quante (eds.) Subjektivität und Anerkennung: Festschrift Ludwig Siep (Paderborn: Mentis Verlag, 2003).

29. See especially John Rawls, Theory of Justice and Justice as Fairness: A Restatement (Cambridge, MA: Harvard University Press, 2001).

3o. See, for example, Bert van den Brink's Chapter 11 in the present volume.

31. Alasdair MacIntyre, Dependent Rational Animals: Why Human Beings Need the Virtues (Chicago: Open Court, 1999).

32. Rawls, A Theory of Justice $§ 24$.

33. Rawls, Justice as Fairness, pp. 171-3.

34. Rawls, Justice as Fairness, p. 19.

35. Rawls, Justice as Fairness, p. 19.

36. Rawls, Justice as Fairness, pp. 18; A Theory of Justice (Cambridge, MA: Harvard University Press, 1971).

37. See, for example, Martha Nussbaum, Women and Human Development: A Capabilities Approach (New York: Cambridge University Press, 200o).

38. Rawls, A Theory of Justice, p. 440.

39. Rawls, A Theory of Justice, p. 128.

40. Rawls, A Theory of Justice, $\S 67$.

41. A related point is made in the discussion of whether liberalism can justifiably insist that societies can do entirely without any (perfectionist) commitment to promoting various qualities and dispositions in their citizenry, such as "civic virtues." See, for example, Raz, Morality as Freedom, and Richard Dagger, Civic Virtues: Rights, Citizenship, and Republican Liberalism (New York: Oxford University Press, 1997) and his chapter (8) in the present volume. 